\title{
Safety and efficacy of vismodegib in patients with basal cell carcinoma nevus syndrome: pooled analysis of two trials
}

Anne Lynn S. Chang ${ }^{1 *}$, Sarah T. Arron², Michael R. Migden ${ }^{3}$, James A. Solomon ${ }^{4,5,6}$, Simon Yoo7, Bann-Mo Day ${ }^{8}$, Edward F. McKenna ${ }^{8}$ and Aleksandar Sekulic ${ }^{9}$

\begin{abstract}
Background: Aberrant activation of the Hedgehog $(\mathrm{Hh})$ pathway is a key driver in the pathogenesis of basal cell carcinomas (BCCs), including patients with BCC nevus syndrome (BCCNS). It is unclear whether BCCs arising in patients with BCCNS respond differently to vismodegib than in patients without BCCNS. We examined the best overall response rate (BORR) and adverse events (AEs) of vismodegib in patients with advanced $\mathrm{BCC}(\mathrm{aBCC})$ with and without BCCNS.
\end{abstract}

Methods: Patients were treated with vismodegib $150 \mathrm{mg} /$ day in the ERIVANCE BCC trial (ClinicalTrials.gov number, NCT00833417) and the expanded access study (EAS; ClinicalTrials.gov number, NCT01160250). BCCNS diagnosis was based on medical history at the time of enrollment. Metastatic BCC response was evaluated using Response Evaluation Criteria In Solid Tumors, version 1.0 (RECIST v1.0) in both studies. Locally advanced BCC was evaluated by a novel composite end point in ERIVANCE BCC and by RECIST V1.0 in the EAS. Response assessments were performed every 8 weeks in ERIVANCE BCC and every 8-16 weeks in the EAS. Safety assessments (National Cancer Institute Common Terminology Criteria for Adverse Events, version 3.0) were performed monthly in both trials. Because of described differences in response assessment/schedule, patients with BCCNS were not pooled across trials. Analytic cohorts for BCCNS and sporadic aBCC were created within each trial for comparison using descriptive statistical methods.

Results: Forty-one patients with BCCNS were included in the study: 22 from ERIVANCE BCC and 19 from the EAS. Investigator-assessed BORR in BCCNS groups ranged from 31 to $81 \%$ in patients with locally advanced BCC $(n=33)$ and was $50 \%$ in patients with metastatic BCC $(n=6)$. These results were comparable with the non-BCCNS groups. Incidence and severity of AEs were also comparable between the BCCNS and non-BCCNS groups. Amenorrhea was observed in both patient cohorts and was reversible in two patients who discontinued treatment.

Conclusion: Vismodegib demonstrated comparable efficacy and safety against aBCC in patients with and without BCCNS.

Keywords: Basal cell carcinoma, Vismodegib, Basal cell carcinoma nevus syndrome

Abbreviations: aBCC, Advanced basal cell carcinoma; AE, Adverse event; BCC, Basal cell carcinoma; BCCNS, Basal cell carcinoma nevus syndrome; BORR, Best overall response rate; Cl, Confidence interval; EAS, Expanded access study; FDA, US Food and Drug Administration; Hh, Hedgehog; HPI, Hedghog pathway inhibitor; laBCC, Locally advanced basal cell carcinoma; mBCC, Metastatic basal cell carcinoma; ORR, Objective response rate; RECIST, Response evaluation criteria in solid tumors; WCBP, Women of childbearing potential

\footnotetext{
* Correspondence: alschang@stanford.edu

'Stanford University, 450 Broadway, Pavilion C, 2nd floor, Redwood City, CA

94063, USA

Full list of author information is available at the end of the article
} 


\section{Background}

First described in patients with basal cell carcinoma (BCC) nevus syndrome (BCCNS), aberrant activation of the Hedgehog $(\mathrm{Hh})$ pathway is a key pathogenic driver in $\mathrm{BCC}[1,2]$. The majority of genetic alterations in the Hh pathway are loss-of-function mutations in the tumor-suppressor gene PTCH1 [2, 3]. Patients with BCCNS develop dozens of BCCs over their lifetimes [4], including unresectable advanced BCCs (aBCCs) that are either locally advanced (laBCC) or metastatic (mBCC).

Therapeutic options are limited for patients with aBCC. Vismodegib, the first Hh pathway inhibitor (HPI) approved by the US Food and Drug Administration (FDA), is indicated for patients who have aBCC that has recurred after surgery or who are not candidates for surgery and radiation [5]. In its pivotal approval study (ERIVANCE BCC), vismodegib demonstrated an overall response rate (ORR) of $43 \%$ in patients with laBCC and $30 \%$ in patients with $\mathrm{mBCC}$ by independent review [5]. In addition, vismodegib reduced the size of existing BCC lesions and prevented development of new lesions compared with placebo in 41 patients with BCCNS with multiple surgically eligible BCCs who were enrolled in an investigator-sponsored trial [6].

It is unclear whether BCCs arising in patients with BCCNS respond differently to vismodegib than in patients without BCCNS. Here, we investigate the efficacy and safety of vismodegib in patients with $\mathrm{aBCC}$ with and without BCCNS enrolled in the ERIVANCE BCC pivotal trial [5] and the US expanded access study (EAS) [7].

\section{Methods}

\section{Study design and treatment}

This was a pooled analysis of two similar open-label clinical trials. ERIVANCE BCC (ClinicalTrials.gov number, NCT00833417) was an international, multicenter, noncomparative phase 2 study. EAS (ClinicalTrials.gov number, NCT01160250) was a multicenter, open-label, noncomparative expanded access study to provide patients with $\mathrm{aBCC}$ access to vismodegib prior to regulatory approval, and was terminated early due to FDA approval. Patients received oral vismodegib $150 \mathrm{mg} /$ day until disease progression, intolerable toxicity, patient withdrawal, or study termination. All patients signed written informed consent.

\section{Key eligibility criteria}

Key eligibility criteria for the ERIVANCE BCC and EAS studies were similar. Patients with $\mathrm{mBCC}$ had histologic confirmation of distant metastasis. Patients with laBCC had $\geq 1$ lesion measuring $\geq 10 \mathrm{~mm}$, inoperable or surgery contraindicated, and prior radiation to $\geq 1$ lesion, unless contraindicated or inappropriate. Other criteria included age $\geq 18$ years, adequate organ function, and Eastern
Cooperative Oncology Group performance status $\leq 2$. Both trials used Response Evaluation Criteria In Solid Tumors, version 1.0 (RECIST v1.0) for assessment of $\mathrm{mBCC}$ and allowed enrollment of patients with BCCNS as long as all other eligibility criteria were met. The EAS also used RECIST v1.0 for assessment of patients with laBCC. ERIVANCE BCC defined response as a $\geq 30 \%$ decrease in the externally visible or radiographic dimension (if applicable) or complete resolution of ulceration (if present at baseline). BCCNS diagnosis was based on medical history at the time of enrollment and/or assessment of clinical investigator.

\section{Assessments \\ Efficacy assessments}

Response assessments were performed every 8 weeks in ERIVANCE BCC and every 8-16 weeks in the EAS.

\section{Safety assessments}

Adverse events (AEs) were assessed on a monthly basis in both trials and graded according to National Cancer Institute Common Terminology Criteria for Adverse events, version 3.0.

\section{Analysis}

All patient data available as of November 26, 2010 for ERIVANCE BCC (primary analysis) and April 23, 2012 for US EAS (final analysis) were included in the analyses. Analytic cohorts for BCCNS and non-BCCNS were created within each trial for comparison using descriptive statistical methods.

Data were not pooled across the trials because of the described differences in the schedule and the criteria for assessment of response. Best ORR (BORR) was analyzed in efficacy-evaluable patients. Clopper-Pearson $95 \%$ confidence intervals (CIs) were computed.

\section{Results \\ Patient characteristics}

The ERIVANCE BCC trial enrolled 104 patients: 71 (68 \%) with laBCC and 33 (32\%) with mBCC. Twentytwo (31\%) patients with BCCNS had laBCC; no patients with BCCNS had mBCC (Table 1). The EAS study enrolled 119 patients: 62 (52\%) with laBCC and 57 (48\%) with mBCC. Twelve (17\%) patients with BCCNS had laBCC; 7 (12 \%) patients with BCCNS had mBCC. Baseline demographic and disease characteristics were generally comparable between patients with and without BCCNS, except for younger age and higher number of women of childbearing potential (WCBP) in the BCCNS cohort. 
Table 1 Patient demographics and baseline disease characteristics ${ }^{a}$

\begin{tabular}{|c|c|c|c|c|c|c|c|}
\hline & \multicolumn{3}{|c|}{ Erivance BCC $(N=104)$} & \multicolumn{4}{|c|}{ EAS $(N=119)$} \\
\hline & \multicolumn{2}{|l|}{$\mathrm{laBCC}$} & \multirow{2}{*}{$\begin{array}{l}\mathrm{mBCC} \\
\text { Non-BCCNS } \\
(n=33)\end{array}$} & \multicolumn{2}{|l|}{$\overline{\mathrm{laBCC}}$} & \multicolumn{2}{|l|}{$\mathrm{mBCC}$} \\
\hline & $\begin{array}{l}\text { BCCNS } \\
(n=22)\end{array}$ & $\begin{array}{l}\text { Non-BCCNS } \\
(n=49)\end{array}$ & & $\begin{array}{l}\text { BCCNS } \\
(n=12)\end{array}$ & $\begin{array}{l}\text { Non-BCCNS } \\
(n=50)\end{array}$ & $\begin{array}{l}\text { BCCNS } \\
(n=7)\end{array}$ & $\begin{array}{l}\text { Non-BCCNS } \\
(n=50)\end{array}$ \\
\hline Median age, years (range) & $47(21-71)$ & $67(38-101)$ & $62(38-92)$ & $52(26-79)$ & 67 (40-92) & $58(37-71)$ & $63(24-100)$ \\
\hline Female, $n(\%)$ & $10(45)$ & $22(45)$ & $9(27)$ & $6(50)$ & $13(26)$ & $3(43)$ & $9(18)$ \\
\hline WCBP, $n(\%)$ & $3(33)$ & $1(2)$ & $2(6)$ & $4(33)$ & $2(4)$ & $1(14)$ & $1(2)$ \\
\hline \multicolumn{8}{|l|}{ ECOG PS, $n(\%)$} \\
\hline $0-1$ & $22(100)$ & $44(90)$ & $32(97)$ & $12(100)$ & $46(92)$ & $7(100)$ & $45(90)$ \\
\hline 2 & 0 & $5(10)$ & $1(3)$ & 0 & $4(8)$ & 0 & $5(10)$ \\
\hline \multicolumn{8}{|l|}{ Target lesions, $n(\%)$} \\
\hline 1 & $13(59)$ & $35(71)$ & $9(27)$ & $4(33)$ & $30(60)$ & $4(57)$ & $20(40)$ \\
\hline 2 & $4(18)$ & $8(16)$ & $4(12)$ & $2(17)$ & $11(22)$ & 0 & $10(20)$ \\
\hline$\geq 3$ & $5(23)$ & $6(12)$ & $20(61)$ & $6(50)$ & $9(18)$ & $3(43)$ & $20(40)$ \\
\hline \multicolumn{8}{|l|}{ Prior treatment, $n(\%)$} \\
\hline Surgery & $21(96)$ & $41(84)$ & $32(97)$ & $12(100)$ & $45(90)$ & $7(100)$ & $47(94)$ \\
\hline Radiotherapy & $1(5)$ & $21(43)$ & $19(58)$ & $1(8)$ & $19(38)$ & $2(29)$ & $33(66)$ \\
\hline Systemic therapy & $5(23)$ & $3(6)$ & $10(30)$ & $2(17)$ & $9(18)$ & $2(29)$ & $18(36)$ \\
\hline Surgery contraindicated, $n(\%)$ & $18(82)$ & $25(51)$ & NA & $7(58)$ & $28(56)$ & NA & NA \\
\hline
\end{tabular}

BCCNS basal cell carcinoma nevus syndrome, EAS expanded access study, ECOG PS Eastern Cooperative Oncology Group performance status, laBCC locally advanced basal cell carcinoma, $M B C C$ metastatic basal cell carcinoma, NA not available, WCBP women of childbearing potential

${ }^{a}$ There were no patients with BCCNS with $\mathrm{mBCC}$ in the ERIVANCE BCC study; therefore, this column is omitted in the table

\section{Treatment exposure}

Median duration of treatment with vismodegib was shorter in the EAS study (5.0-7.1 months across cohorts) than in the ERIVANCE BCC study (9.6-10.5 months across cohorts). Within each trial, the median treatment duration in patients with BCCNS was similar to the duration in patients without BCCNS. Median dose intensity was similar (>97 \%) across all cohorts in both studies.

\section{Best overall response rate}

Similar clinical activity was observed across all cohorts in both studies. In the ERIVANCE BCC study, the investigator-assessed BORR in patients with BCCNS with laBCC was $81 \%$ (95\% CI: 58-95\%); in those without BCCNS, the BORR was $50 \%$ (95 \% CI: 34-66 \%). Although this study suggested that patients with BCCNS with laBCC might be more responsive to vismodegib than patients without BCCNS, this pattern was not observed in the EAS, in which the BORR was $33 \%(95 \%$ CI: 10-65 \%) in patients with BCCNS and $50 \%$ (95\% CI: 35-65 \%) in patients without BCCNS (Table 2).

Among patients with $\mathrm{mBCC}$, the BORR was $46 \%$ (95\% CI: 28-64\%) in patients without BCCNS in the ERIVANCE BCC study; no $\mathrm{mBCC}$ was noted in patients

Table 2 Investigator-assessed BORR (efficacy-evaluable patients) comparing BCCNS and non-BCCNS patient groups

\begin{tabular}{|c|c|c|c|c|c|c|c|}
\hline & \multicolumn{3}{|c|}{ Erivance BCC $(N=96)$} & \multicolumn{4}{|c|}{ EAS $(N=95)$} \\
\hline & \multicolumn{2}{|l|}{$\overline{\mathrm{laBCC}}$} & \multirow{2}{*}{$\begin{array}{l}\mathrm{mBCC} \\
\text { Non-BCCNS } \\
(n=33)\end{array}$} & \multicolumn{2}{|l|}{$\overline{l a B C C}$} & \multicolumn{2}{|l|}{$\mathrm{mBCC}$} \\
\hline & $\begin{array}{l}\text { BCCNS } \\
(n=21)\end{array}$ & $\begin{array}{l}\text { Non-BCCNS } \\
(n=42)\end{array}$ & & $\begin{array}{l}\text { BCCNS } \\
(n=12)\end{array}$ & $\begin{array}{l}\text { Non-BCCNS } \\
(n=44)\end{array}$ & $\begin{array}{l}\text { BCCNS } \\
(n=6)\end{array}$ & $\begin{array}{l}\text { Non-BCCNS } \\
(n=33)\end{array}$ \\
\hline $\begin{array}{l}\text { BORR, } n(\%) \\
{[95 \% \mathrm{Cl}]}\end{array}$ & $\begin{array}{l}17(81) \\
{[58-95]}\end{array}$ & $\begin{array}{l}21(50) \\
{[34-66]}\end{array}$ & $\begin{array}{l}15(46) \\
{[28-64]}\end{array}$ & $\begin{array}{l}4(33) \\
{[10-65]}\end{array}$ & $\begin{array}{l}22(50) \\
{[35-65]}\end{array}$ & $\begin{array}{l}3(50) \\
{[12-88]}\end{array}$ & $\begin{array}{l}9(27) \\
{[13-46]}\end{array}$ \\
\hline Complete response & $8(38)$ & $12(29)$ & 0 & $1(8)$ & $5(11)$ & $2(33)$ & 0 \\
\hline Partial response & $9(43)$ & $9(21)$ & $15(46)$ & $3(25)$ & $17(39)$ & $1(17)$ & $9(27)$ \\
\hline Stable disease & $3(14)$ & $12(29)$ & $15(46)$ & $6(50)$ & $21(48)$ & $3(50)$ & $17(52)$ \\
\hline Progressive disease & $1(5)$ & $5(12)$ & $2(6)$ & $2(17)$ & 0 & 0 & $3(9)$ \\
\hline Not evaluable or missing & 0 & $4(10)$ & $1(3)$ & $2(17)$ & $1(2)$ & 0 & $4(12)$ \\
\hline
\end{tabular}

$B C C N S$ basal cell carcinoma nevus syndrome, BORR best overall response rate, $C$ confidence interval, EAS expanded access study, laBCC locally advanced basal cell carcinoma, $m B C C$ metastatic basal cell carcinoma 
with BCCNS. In the EAS, patients with BCCNS with mBCC had a BORR of $50 \%$ (95\% CI: $12-88 \%)$ and those without BCCNS had a BORR of $27 \%$ (95 \% CI: $13-46 \%)$.

\section{Safety}

No consistent trends in the incidence of AEs were observed across studies. The most frequent AEs in patients with BCCNS were alopecia (86 and $58 \%$ in ERIVANCE $\mathrm{BCC}$ and the EAS, respectively), muscle spasms (77 and $63 \%$ ), weight decrease (68 and $5 \%$ ), and dysgeusia (59 and $74 \%$ ) (Table 3). The most frequent AEs in patients with non-BCCNS aBCC were alopecia (57 and $58 \%$ in ERIVANCE BCC and the EAS, respectively), muscle spasms (66 and $72 \%$ ), weight decrease (40 and $18 \%$ ), and dysgeusia (49 and $70 \%$ ) (Table 3). The longer period of follow-up for ERIVANCE BCC compared with the EAS likely accounts for differences in later-onset AEs such as weight decrease. In both studies, there were lower percentages of dysgeusia in patients with BCCNS compared with patients without BCCNS. Incidences of grade 3-5 AEs were $41 \%$ in the BCCNS group versus $43 \%$ in the non-BCCNS group in ERIVANCE BCC, and $16 \%$ versus $32 \%$ in the EAS.

For WCBP, amenorrhea or irregular menstruation was reported in 2/3 (67 \%) and 0/3 patients with and without BCCNS, respectively, in the ERIVANCE BCC study. It was reported in 2/5 (40\%) and 2/3 (67\%) patients with and without BCCNS, respectively, in the EAS.

\section{Discussion}

Vismodegib demonstrated clinical activity across all cohorts, including patients with BCCNS, confirming the efficacy of HPIs in these patients [2,3]. While numerical

Table 3 Most common adverse events stratified by BCCNS or non-BCCNS status

\begin{tabular}{|c|c|c|c|c|}
\hline \multirow[t]{2}{*}{$\begin{array}{l}\text { Selected AEs, } \\
n(\%)\end{array}$} & \multicolumn{2}{|c|}{$\begin{array}{l}\text { Erivance BCC } \\
(N=104)\end{array}$} & \multicolumn{2}{|c|}{$\begin{array}{l}\text { EAS } \\
(N=119)\end{array}$} \\
\hline & $\begin{array}{l}\text { BCCNS } \\
(n=22)\end{array}$ & $\begin{array}{l}\text { Non-BCCNS } \\
(n=82)\end{array}$ & $\begin{array}{l}\text { BCCNS } \\
(n=19)\end{array}$ & $\begin{array}{l}\text { Non-BCCNS } \\
(n=100)\end{array}$ \\
\hline Any AE & $22(100)$ & $82(100)$ & $18(95)$ & $98(98)$ \\
\hline Grade 3-5 AE & $9(41)$ & $35(43)$ & $3(16)$ & $32(32)$ \\
\hline Alopecia & $19(86)$ & $47(57)$ & $11(58)$ & $58(58)$ \\
\hline Muscle spasms & $17(77)$ & $54(66)$ & $12(63)$ & $72(72)$ \\
\hline Weight decreased & $15(68)$ & $33(40)$ & $1(5)$ & $18(18)$ \\
\hline Dysgeusia & $13(59)$ & $40(49)$ & $14(74)$ & $70(70)$ \\
\hline Nausea & $9(41)$ & $21(26)$ & $3(16)$ & $20(20)$ \\
\hline Fatigue & $8(36)$ & $29(35)$ & $7(37)$ & $16(16)$ \\
\hline Diarrhea & $7(32)$ & $16(20)$ & $3(16)$ & $27(27)$ \\
\hline Arthralgia & $5(23)$ & $11(13)$ & $2(11)$ & $2(2)$ \\
\hline
\end{tabular}

$A E$ adverse event, $B C C N S$ basal cell carcinoma nevus syndrome, EAS expanded access study differences in BORR were observed across cohorts, they were not consistent trends that were clinically significant. Rather, differences were likely due to similar but nonidentical response criteria, treatment duration, and length of follow-up in each study, as well as biologic factors that may affect treatment response (e.g., tumoral heterogeneity, presence of SUFU mutation).

Numerical differences were also observed between cohorts with respect to the incidence of various AEs; however, no consistent patterns were observed across the two studies. As patients with BCCNS tend to be younger than those without BCCNS, BCCNS cohorts also tend to include a higher proportion of WCBP than non-BCCNS cohorts. A survey of six phase 1 and 2 Roche-sponsored studies of vismodegib that included WCBP determined that irregular menses or amenorrhea occurred in 10 (28.5\%) of 35 premenopausal women (inclusive of the women presented in this analysis), eight of whom had BCCNS [8]. An analysis by BCCNS status was not performed. Results of hormonal evaluation were available for four patients after the onset of irregular menses or amenorrhea; two had normal values (premenopausal), one patient was considered postmenopausal, and one had elevated follicle-stimulating hormone, elevated luteinizing hormone, and normal estradiol values [8]. Menses resumed in two patients who discontinued vismodegib, suggesting that amenorrhea observed with vismodegib treatment might be reversible.

When stratified for BCCNS status in this analysis, amenorrhea was observed in WCBP in both groups. The mechanism responsible has yet to be fully elucidated, although the Hh pathway is known to play a role in follicular development and patients with BCCNS frequently develop ovarian cysts $(25-50 \%$ of patients) [4, 9]. Additionally, a recent case report suggested that vismodegib might induce amenorrhea by blockading follicle-stimulating hormone receptor-dependent signal transduction [10].

\section{Conclusions}

Vismodegib demonstrates clinical activity in patients with aBCC with and without BCCNS. Overall, the safety profile was similar in both groups, an important consideration when counseling patients.

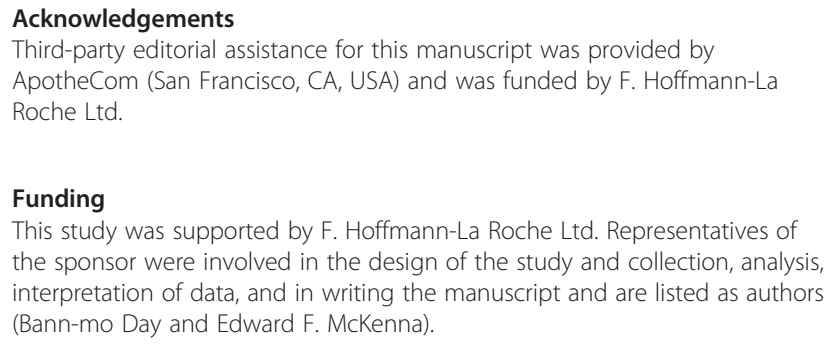
interpretation of data, and in writing the manuscript and are listed as authors (Bann-mo Day and Edward F. McKenna). 


\section{Availability of data and material}

The primary data for these studies have been published previously and include supporting online data and study protocols.

\section{Authors' contributions}

AC participated in data collection, analysis, interpretation, and manuscript revision. SA contributed to data acquisition, interpretation of results, revision of the manuscript for intellectual content, and final approval of the version to be published. MM contributed to the conception, design, and drafting of the work; the acquisition, analysis, and interpretation of the data; and critical revision for intellectual content. JS contributed to the conception, design, and drafting of the work; the acquisition, analysis, and interpretation of the data; and critical revision for intellectual content. SY contributed to the conception, design, and drafting of the work; the acquisition, analysis, and interpretation of the data; and critical revision for intellectual content. BD contributed to design of the study, writing of the statistical analysis plan, generation and interpretation of the data, and drafting of the reports based on critical information from the work. EM made substantial contributions to the project, including conception/design of the work, analysis, and interpretation of data. AS contributed to the conception, design, and drafting of the work; the acquisition, analysis, and interpretation of the data; and critical revision for intellectual content. All authors read and approved the final manuscript.

\section{Competing interests}

A S Chang is a clinical investigator on clinical trials sponsored by F. HoffmannLa Roche and Genentech. K D Lewis declares no competing interest. S T Arron has received honoraria for advisory boards from Roche and Leo Pharma, salary support as an investigator from Genentech, Anacor, and Allergan, and salary support as a consultant from Portola Pharmaceutical. M R Migden has received honoraria for advisory boards from Genentech, Novartis, and Lilly. J A Solomon has received honoraria for advisory boards from Genentech and Lilly, and has served as an investigator on Genentech trials. S Yoo has received honoraria as a consultant for Genentech, AbbVie, and Castle Biosciences, and owns stock in Woundcare Technology. B-M Day is a salaried employee of Genentech. E McKenna receives salary and stock/stock options as an employee of Genentech. A Sekulic has served on advisory boards for Roche/Genentech (no personal compensation).

\section{Consent for publication}

Not applicable.

\section{Ethics approval and consent to participate}

Both studies were reviewed and approved by the respective institutional review boards or ethics committees of participating centers and all patients provided written informed consent prior to participation in the study.

\section{Author details}

${ }^{1}$ Stanford University, 450 Broadway, Pavilion C, 2nd floor, Redwood City, CA 94063, USA. 'University of California, San Francisco, 1701 Divisadero Street, Box 0316, San Francisco, CA 94115, USA. ${ }^{3}$ The University of Texas MD Anderson Cancer Center, Unit 1452, 1400 Pressler Street, Houston, TX 77030, USA. ${ }^{4}$ Ameriderm Research, 725 West Granada Boulevard, Suite 44, Ormond Beach, FL 32174, USA. ${ }^{5}$ University of Central Florida, Cl6850 Lake Nona Boulevard, Orlando, FL 32827, USA. ${ }^{6}$ University of Illinois, 506 South Mathews Avenue, Urbana, IL 61801, USA. ${ }^{7}$ Northwestern University, 676 North St. Clair Street, Suite 1600, Chicago, IL 60611, USA. ${ }^{8}$ Genentech, Inc., 1 DNA Way, South San Francisco, CA 94080, USA. ${ }^{9}$ Mayo Clinic, 13400 East Shea Boulevard, Scottsdale, AZ 85259, USA.

Received: 8 April 2016 Accepted: 23 August 2016 Published online: 01 September 2016

\section{References}

1. Epstein EH. Basal cell carcinomas: attack of the hedgehog. Nat Rev Cancer. 2008;8(10):743-54

2. Göppner D, Leverkus M. Basal cell carcinoma: from the molecular understanding of the pathogenesis to targeted therapy of progressive disease. J Skin Cancer. 2011;2011:650258.
3. Sekulic A, Mangold AR, Northfelt DW, LoRusso PM. Advanced basal cell carcinoma of the skin: targeting the hedgehog pathway. Curr Opin Oncol. 2013;25(3):218-23

4. Lo Muzio L. Nevoid basal cell carcinoma syndrome (Gorlin syndrome). Orphanet J Rare Dis. 2008;3:32.

5. Sekulic A, Migden MR, Oro AE, Dirix L, Lewis KD, Hainsworth JD, et al. Efficacy and safety of vismodegib in advanced basal-cell carcinoma. N Engl J Med. 2012;366(23):2171-9.

6. Tang JY, Kay-Wiggan JM, Aszterbaum M, Yauch RL, Lindgren J, Chang K, et al. Inhibiting the hedgehog pathway in patients with the basal-cell nevus syndrome. N Engl J Med. 2012;366(23):2180-8.

7. Chang AL, Solomon JA, Hainsworth JD, Goldberg L, McKenna E, Day BM, et al. Expanded access study of patients with advanced basal cell carcinoma treated with the Hedgehog pathway inhibitor, vismodegib. J Am Acad Dermatol. 2014:70(1):60-9.

8. Sekulic A, Weiss GJ, Solomon JA, Rudin CM, Guillot B, Williams S, et al. Amenorrhea or irregular menses in patients treated with vismodegib. Presented at: 2014 Winter Clinical Dermatology Conference Hawaii; Kohala Coast, Hawaii. 2014

9. Spicer L, Sudo S, Aad PY, Wang LS, Chun SY, Ben-Shlomo I, et al. The hedgehog-patched signaling pathway and function in the mammalian ovary: a novel role for hedgehog proteins in stimulating proliferation and steroidogenesis of theca cells. Reproduction. 2009;138(2):329-39.

10. Strasswimmer J, Latimer B, Ory S. Amenorrhea secondary to a vismodegib-induced blockade of follicle-stimulating hormone-receptor activation. Fertil Steril. 2014;102(2):555-7.

\section{Submit your next manuscript to BioMed Central and we will help you at every step:}

- We accept pre-submission inquiries

- Our selector tool helps you to find the most relevant journal

- We provide round the clock customer support

- Convenient online submission

- Thorough peer review

- Inclusion in PubMed and all major indexing services

- Maximum visibility for your research

Submit your manuscript at www.biomedcentral.com/submit
Biomed Central 